\title{
Como as necessidades de informação podem se relacionar com as competências informacionais
}

\author{
Silvânia Miranda \\ Doutora em ciência da informação. \\ E-mail: silvaniavm@terra.com.br
}

\begin{abstract}
Resumo
O presente artigo busca discutir uma conexão teórica entre os temas necessidades de informação e competência informacional. Dois construtos teóricos são apresentados de forma a expressar as semelhanças identificadas entre as dimensões das necessidades de informação e das competências, possibilitando o estabelecimento de uma ligação teórica em um terceiro construto. Repercussões dessa conexão teórica são aventadas, considerando-se que o reconhecimento de necessidades de informação pode corresponder, na prática, ao desenvolvimento de competências informacionais que possam atendê-las. Dessa forma, poder-se-ia proporcionar empowerment aos usuários de informação, no sentido de que fossem capazes de atender a suas próprias necessidades de informação desenvolvendo eles próprios as competências para tal.
\end{abstract}

\section{Palavras-chave}

Necessidades de informação. Competência. Competência informacional.

\section{How the information needs may be related to information compentency}

\begin{abstract}
This paper intends to discuss a theoretical connection between information needs and information competencies. Two theoretical models are presented to express the similarities identified between the dimensions and elements of information needs and competencies. A third model presents a possibility of connection. Aspects of possible issues following this theoretical construction are discussed, considering that the recognition of information needs may result, practically speaking, on the development of informational competencies to fulfill these needs. In this way, information users could be empowered; in the sense that they would be able to fulfill their own information needs developing themselves suitable information competency.
\end{abstract}

\section{Keywords}

Information needs. Competencies. Information competency.

\author{
INTRODUÇÃO
}

Tentar compreender as necessidades informacionais (NI) e as competências como temas relacionados, não somente por meio de suas dimensões teóricas constitutivas, mas também de um ponto de vista prático, é o objetivo do estudo. Considera-se que o reconhecimento das NIs não é bastante para satisfazê-las. É necessário proporcionar ao usuário não só a capacidade de entender suas próprias NI, mas também de satisfazê-las e, se possível, com seus próprios meios. $\mathrm{O}$ desenvolvimento de competências específicas relacionadas ao trabalho informacional pode fazer parte de um esforço para proporcionar ao usuário os recursos necessários para lidar com a informação que lhe faz falta e para resolver seus problemas informacionais.

O texto está composto da exposição sobre os temas necessidades de informação e competências no nível individual, da proposição de um referencial teórico que relaciona esses temas e de algumas considerações sobre as possibilidades abertas a partir desse referencial. Não se tratou, neste texto, das influências exercidas pelo ambiente organizacional, dado o pouco espaço disponível para exposições mais complexas e longas.

\section{AS NECESSIDADES DE INFORMAÇÃO}

\section{Literatura sobre necessidades de informação}

Os estudos de usuários* já acumularam grande número de pesquisas e contam com importante instrumento de revisão e análise representado pelo Annual Review of Information Science and Technology (Arist). Apesar de concentrar-se nos trabalhos publicados em língua inglesa, as revisões do Arist são ricas em apontar características, tendências e variáveis importantes nos estudos das necessidades e usos de informação. As revisões do Arist realizadas até 1986 apontavam falta de refinamento conceitual e metodológico, bem como pouca consideração sobre o ambiente de uso da informação e sobre a distinção entre os aspectos cognitivos e sociais da informação**

\footnotetext{
* Os estudos de usuários podem ser considerados como um método de sondagem objetiva que abrange o estudo das "necessidades de informação" e os "usos da informação". Esses estudos remontam à década de 1940 e foram iniciados para responder à explosão de informações científicas e novas tecnologias, normalmente realizados por bibliotecários ou administradores de centros de informação ou laboratórios que precisavam de dados para planejar seu serviço (WILSON, 1981; CHOO, 2003).

** Para uma revisão bibliográfica dos estudos anteriores a 1986, consultar Bettiol (1988) e Walter (1988).
} 
As revisões Arist pós 1986 identificaram uma mudança de paradigma na área e o aparecimento de estudos que consideravam o usuário como ponto central de análise, e não os sistemas de informação. Dervin e Nilan (1986) concluíram que era necessário mudar o paradigma tradicional e desenvolver uma forma alternativa para os estudos de necessidades e usos da informação. Foram detectados novos direcionamentos apontando para as seguintes tendências:

- as necessidades dos usuários deveriam se tornar o foco central da operação de sistemas;

- os serviços de informação deveriam ser ajustados às necessidades específicas do indivíduo, e não o contrário;

- deveria ser mudado o foco dos sistemas de informação dirigidos a tecnologias e conteúdos para os dirigidos aos usuários;

- deveria ser colocado o foco nos próprios usuários.

As diferenças nos conceitos de informação e de necessidade de informação que caracterizavam os paradigmas da pesquisa tradicional e da pesquisa alternativa estão resumidas na tabela 1 . Dervin e Nila destacaram três abordagens como pertencentes ao novo paradigma dos estudos de necessidades e usos da informação, cujas características encontram-se na tabela 2, que identifica alguns autores que as adotaram.

\section{TABELA 1}

Comparação entre os conceitos de informação e necessidades de informação na pesquisa tradicional e na alternativa

\begin{tabular}{l|l}
\multicolumn{1}{c|}{$\begin{array}{c}\text { PESQUISA } \\
\text { TRADICIONAL }\end{array}$} & \multicolumn{1}{c}{$\begin{array}{c}\text { PESQUISA } \\
\text { ALTERNATIVA }\end{array}$} \\
\hline $\begin{array}{l}\text { INFORMAÇÃO: proprie- } \\
\text { dade da matéria, mensagem, } \\
\text { documento ou recurso infor- } \\
\text { macional, qualquer material } \\
\text { simbólico publicamente dis- } \\
\text { ponível. }\end{array}$ & $\begin{array}{l}\text { estímulo que altera a estrutura cog- } \\
\text { transforma do receptor. }\end{array}$ \\
\hline $\begin{array}{l}\text { NECESSIDADE DE IN- } \\
\text { FORMAÇÃO: estado de } \\
\text { necessidade de algo que o } \\
\text { pesquisador chama de infor- } \\
\text { mação, focada no que o sis- } \\
\text { tema possui, e não no que o } \\
\text { usuário precisa. }\end{array}$ & $\begin{array}{l}\text { que existe algo errado em seu estado } \\
\text { de conhecimento e deseja resolver } \\
\text { essa } \\
\text { conhecimento abaixo do necessário, } \\
\text { estado de conhecimento insuficiente } \\
\text { para lidar com incerteza, conflito e } \\
\text { lacunas em uma área de estudo ou } \\
\text { trabalho. }\end{array}$ \\
\hline
\end{tabular}

Fonte: Dervin e Nilan (1986, p. 17).

\section{TABELA 2}

\section{Principais abordagens alternativas em pesquisas sobre necessidades e usos da informação}

\begin{tabular}{|c|c|c|}
\hline ABORDAGEM & $\begin{array}{c}\text { AUTORES QUE } \\
\text { UTILIZARAM }\end{array}$ & CARACTERÍSTICAS DA ABORDAGEM \\
\hline Valor Adicionado & $\begin{array}{l}\text { Taylor, MacMullin, Hall, } \\
\text { Ford, Garvey, Mohr, } \\
\text { Paisley, Farradane }\end{array}$ & $\begin{array}{l}\text { Foco na percepção da utilidade e valor que o usuário traz para o sistema. } \\
\text { Pretende fazer do problema do usuário o foco central, identificando diferentes } \\
\text { classes de problemas e ligando-os aos diferentes traços que os usuários estão } \\
\text { dispostos a valorizar quando enfrentam problemas. É um trabalho de orientação } \\
\text { cognitiva em processamento da informação. (problema } \rightarrow \text { valores cognitivos } \\
\rightarrow \text { soluções) }\end{array}$ \\
\hline Construção de Sentido & $\begin{array}{l}\text { Dervin, Fraser, } \\
\text { Edelstein, Grunig, } \\
\text { Stamm, Atwood, } \\
\text { Palmour, Carter, } \\
\text { Dewdney, Warner, } \\
\text { Chen, Burger, Hernon. }\end{array}$ & $\begin{array}{l}\text { Conjunto de premissas conceituais e teóricas para analisar como pessoas } \\
\text { constroem sentido nos seus mundos e como elas usam a informação e outros } \\
\text { recursos nesse processo. Procura lacunas cognitivas e de sentido expressas em } \\
\text { forma de questões que podem ser codificadas e generalizadas a partir de dados } \\
\text { diretamente úteis para a prática da comunicação e informação. (situação } \rightarrow \\
\text { lacuna cognitiva e de sentido } \rightarrow \text { uso) }\end{array}$ \\
\hline
\end{tabular}


Existem similaridades entre as abordagens, e todas elas procuram isolar o que o usuário vê como dimensão fundamental de uma situação-problema, e o que pode ser relatado por diferentes estratégias cognitivas que os usuários utilizam para determinar que tipo de informação lhes será útil. Hewins (1990) atualizou a revisão de 1986, ressaltando a busca por uma estrutura conceitual como um tema contínuo e a dispersão da literatura existente por diversas áreas com preocupações, métodos e objetivos diferentes, o que dificultava uma unidade conceitual. $\mathrm{Na}$ área de biblioteconomia e ciência da informação, Hewins ressalta os trabalhos que consideram os estados cognitivos e afetivos do usuário, e os trabalhos que tratam da transferência da informação. Outro fato novo apontado foi o aparecimento de maior uso de metodologias qualitativas entre os estudos revisados.

Pettigrew et al. (2001) revisaram a literatura pós-1990, sob o tema "comportamento informacional", que define como as pessoas necessitam, buscam, fornecem e usam a informação em diferentes contextos, incluindo o espaço de trabalho e a vida diária. Essa definição foi considerada consistente com o que pode ser denominado: a totalidade do comportamento humano em relação a fontes e canais de informação, incluindo as buscas passiva e ativa e o uso da informação, o que parece refletir a inclusão do tema NI como uma parte do estudo sobre comportamento informacional*.

Os autores enfatizaram a busca de teorias, ou de um conjunto coerente e explícito de suposições, definições e proposições com poder explicativo, ressaltando a prevalência da abordagem cognitiva. Os trabalhos revisados foram classificados de acordo com a base teórica em três abordagens: cognitivas (em que o indivíduo é o foco), sociais (em que o contexto é o foco) e multifacetadas (que focam o indivíduo e o contexto ao mesmo tempo). A conclusão foi que parece estar emergindo um corpo teórico distinto, teoricamente unificado, no qual a construção de modelos e estruturas holísticas, compreensivas e multifacetadas pode ocorrer. Este corpo teórico enfatiza a influência contextual dos fatores cognitivos, sociais, culturais, afetivos e lingüísticos; além de centrar-se no usuário, considerando o fenômeno do comportamento informacional como parte do processo de

\footnotetext{
*Deve-se ressaltar que o uso da denominação "comportamento informacional" foi debatido, por um lado, porque pode sugerir uma ligação com a corrente teórica do comportamentalismo e, por outro, porque alguns autores consideram que ele não expressa a diversidade de subtemas dessa área de estudo (PETTIFREW et al., 2001)
}

comunicação humana ${ }^{*}$. Foi também sinalizado, nessa última revisão, que novos temas haviam surgido na área de estudo de usuários: aquisição incidental de informação; importância das tarefas no trabalho informacional nas organizações; "horizontes informacionais"; inclusão da tecnologia nas proposições teóricas etc.

\section{Literatura brasileira sobre necessidades de informação}

Na literatura brasileira sobre estudos de usuários, existem alguns trabalhos de revisão e suas conclusões não são diferentes daquelas das revisões Arist. Pinheiro (1982) revisou a literatura em busca de uma base conceitual para a área e concluiu que havia poucos estudos, faltando experiência na área. Ou seja, faltava uma base teórica mais profunda e aperfeiçoamento metodológico, pois os estudos brasileiros restringiam-se, de modo geral, a uma das facetas do usuário, que era o perfil.

Ferreira (1997) revisou os paradigmas de estudos de usuários, considerando as abordagens do "Valor Agregado" (Taylor, 1986), "Estado de Conhecimento Anômalo" (Belkin et al., 1982), e desdobrou a abordagem da Construção de Sentido em duas vertentes - "Processo Construtivista" (Kuhlthau, 1993) e "sense-making" (Dervin, 1998). Para a autora, a abordagem sense-making estava além das outras três porque apresentava suposições ontológicas e epistemológicas para basear a definição do fenômeno chamado "sense-making". Este fenômeno seria caracterizado pela tríade "situação-lacuna-uso", gerando um modelo de compreensão do processo de relacionamento entre um usuário e a informação. $\mathrm{O}$ sense-making pressupõe atributos: individualidade (subjetividade); situacionalidade (histórico pessoal); utilidade da informação (para a compreensão da situação); padrões (processos cognitivos comuns).

Figueiredo (1983) revisou os conceitos de necessidade, demanda e uso da informação. Para a autora, eles dependiam dos valores da sociedade, da expectativa de satisfação, da disponibilidade e acessibilidade; sendo, portanto, difícil estabelecer relações entre as necessidades, as demandas e os usos da informação. Foram três os conceitos oferecidos pela autora: a) necessidade é o que o indivíduo deve ter para o seu trabalho, pesquisa, edificação, recreação etc., sendo uma demanda em potencial; b) demanda é o que o indivíduo pede, o item

\footnotetext{
* Segundo Kuhlthau e Vakkari (1999, p. 723), o construtivismo (individual e social) é a estrutura teórica que parece permear a maioria dos estudos de usuários, com uma visão holística das NIs na vida das pessoas.
} 
de informação requisitado, sendo um uso em potencial; c) o uso é aquilo que o indivíduo realmente utiliza, podendo ser indicadores parciais de uma demanda e representarem uma necessidade.

\section{O trabalho de Wilson, Le Coadic, Calva Gonzáles e Choo}

Alguns autores não foram analisados nas revisões Arist ou tiveram poucos de seus trabalhos incluídos: T.D. Wilson, Y.F. Le Coadic, J.J. Calva Gonzáles, C.W. Choo. As pesquisas desses autores poderiam fazer parte do conjunto denominado pesquisa alternativa, pois eles consideram que a necessidade de informação (NI) apresenta o aspecto de construção de sentido, além de estar ligada à percepção de estados "anômalos" de conhecimento no confronto com problemas ou situações-problema.

Calva Gonzáles (2004) revisou, principalmente, a literatura de origem latino-americana e estudou o fenômeno das NIs considerando-as em três fases principais: o surgimento, o comportamento de busca e a satisfação das necessidades. Segundo suas pesquisas, a maior parte dos estudos publicados não são realmente estudos de NIs. Dos trabalhos que realmente abordaram o fenômeno das NIs, poucos se dedicaram às fases do surgimento das NIs ou da satisfação dos usuários, a maioria era referente a comportamentos informacionais*. Outra característica apontada pelo autor é que as investigações focaram principalmente os usuários reais, deixando de lado os usuários potenciais, que seriam, normalmente, a maioria da população considerada.

Para Le Coadic (1998), até meados da década de 1990, os estudos ditos de NI e de usos e usuários de informação raramente eram estudos de necessidades de informação. Para esse autor, apenas $24 \%$ dos 241 artigos publicados entre 1990 e 1994 continham algo sobre os processos cognitivos dos usuários e apresentavam uma abordagem parcial das NIs. Tratava-se, em maioria, de estudos de usos de sistemas de informação por meio de usuários, não se fazendo distinção entre necessidade e uso de informação. Para estabelecer um novo paradigma, os

\footnotetext{
* Talvez a concentração dos estudos de NI individuais na fase referente ao comportamento informacional reflita, da mesma forma que apontam as revisões da literatura de estudos organizacionais, estreita ligação com a proveniência da literatura dominante na área, que é de língua inglesa e principalmente americana. $\mathrm{Na}$ literatura de língua inglesa, predominam as correntes filosóficas funcionalistas e comportamentalistas. Como a linha teórica dominante influencia a literatura de outros países, acaba por se tornar um viés ao qual se prende a maioria das pesquisas realizadas.
}

novos estudos deveriam estar interessados na maneira pela qual um usuário analisa suas necessidades, entra em contato com um sistema de informação e constrói sentido, implicando a separação entre os estudos das NIs e dos usos da informação.

As NIs traduzem um estado de conhecimento no qual alguém se encontra quando se confronta com a exigência de uma informação que lhe falta e lhe é necessária para prosseguir um trabalho. Ela nasce de um impulso de ordem cognitiva, conduzido pela existência de um dado contexto (um problema a resolver, um objetivo a atingir) e pela constatação de um estado de conhecimento insuficiente ou inadequado. A NI é uma necessidade derivada, comandada pela realização de uma necessidade fundamental. Ela é também evolutiva e extensiva, porque muda com o tempo sob o efeito da exposição às diferentes informações iniciais e é produzida dinamicamente gerando novas necessidades. A NI não pode estar separada do contexto, da situação, do ambiente, que são essenciais para estabelecer o seu diagnóstico (Le COADIC,1998).

O comportamento informacional pode ser definido como a totalidade do comportamento em relação a fontes e canais de informação, incluindo a busca passiva e ativa e o uso de informação. Uma nova perspectiva para o usuário da informação deveria partir da crença de que a quantidade de informação que se recebe não é função do número de páginas lidas, por exemplo, mas dos processos mentais de entendimento e integração de dados na estrutura pessoal de conhecimento; o que coloca em pauta a perspectiva cognitiva do usuário. Além disso, existem ambientes sociais e organizacionais que envolvem o usuário e que afetam a motivação individual, os usos da informação e seus fluxos. Um modelo de estudo de usuário deve começar com um modelo da organização em que ele trabalha e com o entendimento de como isso afeta o comportamento individual de busca de informação. Deve-se levar em conta a estrutura, as tarefas, a tecnologia e as pessoas em uma constante interrelação, em que a mudança de um fator altera os outros (WILSON, 2000).

Grande quantidade de necessidades humanas pessoais está na raiz da motivação pelo comportamento de busca de informação, indicando que elas são inter-relacionadas, gerando, conjuntamente, o engajamento na busca por informações. As necessidades nascem dos papéis dos indivíduos na vida social, e o mais relevante desses papéis é o papel exercido no trabalho. Esse papel representa um conjunto de atividades, responsabilidades etc. de um 
indivíduo na busca de seu sustento e outras satisfações. Assim, a necessidade de resultados em uma tarefa particular e os processos de planejamento e tomada de decisão serão os principais geradores de necessidades cognitivas; enquanto a natureza do ambiente, combinada com a estrutura da personalidade individual, cria as necessidades afetivas (WILSON,1981).

Entre os fatores determinantes que relacionam as necessidades e o comportamento de busca da informação devem ser incluídos aspectos do ambiente onde o "papel trabalho" é desempenhado: clima econômico, sistema político, ambiente físico. As estruturas mentais preexistentes nas quais uma informação toma forma estão ligadas ao mundo social e organizacional no qual está inserido o usuário e que lhe fornecem condições para a construção de significados. Os postulados básicos do modelo de comportamento informacional de Wilson são considerar pessoas em seu contexto, considerar variáveis intervenientes com três categorias (individual, social e ambiental), considerar o comportamento com característica cíclica, e adotar abordagem multidisciplinar na explicação do comportamento informacional (WILSON,1981; 1983; 2002; NIEDZWIEDZKA, 2003).

Características pessoais influenciam a escolha e a hierarquia das NIs e quão fortes elas são. Influem também nas condições cognitivas como conseqüência de papéis sociais e profissionais que estabelecem características de comportamento ou por indução das condições do ambiente. As características dos papéis profissionais estão conectadas com a posição ocupada, tipo de trabalho e hierarquia profissional; e a estrutura organizacional (incluindo os sistemas e serviços de informação, situação econômica, tecnologia, cultura, tradição etc.) é característica do ambiente que influencia no comportamento. As características das fontes formais e informais de informação também podem influenciar na ocorrência e tipo de necessidade, afetando a percepção das barreiras à informação e as maneiras pelas quais as necessidades podem ser atendidas (NIEDZWIEDZKA, 2003).

Nem toda necessidade se transforma em uma atividade de busca de informação, devendo haver mecanismos de ativação para que ele se efetive. Certos mecanismos podem (ou não) induzir a busca de informação de acordo com a crença da pessoa. Se existir a crença de já se possuírem informações suficientes para decidir, não haverá busca por mais informações (teoria do stress). Outro mecanismo é a necessidade de lidar com uma situação ou resolver um problema: o custo ou o benefício percebido no processo de busca levará a pessoa a decidirse por se engajar ou não na busca efetiva pela informação.
O processo de busca e uso da informação indica uma atividade construtiva de sentido para as situações de mudança pelas quais a pessoa passa para solucionar problemas e nos quais o senso individual parece haver esgotado (WILSON, 1996; FERREIRA, 1997). Ou seja, a necessidade surge da falta de sentido percebida nas situações enfrentadas, causando uma lacuna de sentido que se busca preencher com o uso de informações.

Pode-se usar a informação em três arenas básicas: na criação de significados para o entendimento do seu ambiente de atuação; na construção de conhecimentos para suprir lacunas de conhecimento e desenvolver novas competências; na tomada de decisões para escolher formas de ação. A geração e transformação da informação são moldadas pela cultura e pela especificação de regras, rotinas e papéis. Informações e significados são forjados nos pensamentos, sentimentos e ações dos indivíduos, em um processo cíclico. A administração do ciclo da informação gera mais informação, que por sua vez gera conhecimento; que subsidia a estratégia fornecendo base para a ação; e que fornece o feedback necessário para recomeçar o processo. Assim, a administração da informação deve ser vista como a administração de uma rede de processos que adquirem, criam, organizam, distribuem e usam a informação num ciclo contínuo (CHOO, 2003; 2006).

As pessoas usam a informação para resolver problemas ou desenvolver uma tarefa. $\mathrm{O}$ ambiente social na qual a informação é encontrada determina seu valor e sua importância. Quando tratamos a informação como subjetivamente construída, estamos preocupados em entender os processos sociais e comportamentais nos quais a informação se estrutura e funciona. Grupos distintos de pessoas têm diferentes necessidades e hábitos de busca de informação, bem como estilos diferentes de processar a informação. Ao buscar e usar a informação, as pessoas estão continuamente construindo sentido a respeito do ambiente e, fazendo isso, parecem empregar estratégias básicas, dependendo do tipo de situação e de NIs em que se encontram (CHOO, 1999; AUSTER; $\mathrm{CHOO}, 1996)$.

Os processos de busca e uso da informação são construídos cognitiva e emocionalmente, como também de forma situacional e dinâmica (o contexto define normas, convenções e práticas que moldam comportamento). A busca e o uso da informação dependem de como o indivíduo avalia a relevância cognitiva e emocional da informação recebida e de atributos objetivos capazes de determinar a pertinência da informação a certa situação problemática. Diferentes pessoas ou grupos têm diferentes 
idéias sobre o que constitui a solução de um problema. Atributos físicos e sociais influenciam no uso da informação porque especificam o seu ambiente de uso: familiaridade da situação; o tempo disponível; o quanto a informação pode ser útil; a qualidade do processo e dos resultados da busca. As NIs são determinadas pela percepção de lacunas no conhecimento e a capacidade de dar sentido ao lidar com problemas ou tarefas; por fatores emocionais inerentes à incerteza, nível de stress e dificuldade existentes ao perceber essas lacunas, bem como por fatores situacionais encontrados em contextos e experiências específicos: clareza e consenso quanto aos objetivos; restrição de recursos; magnitude de riscos; formas de controle; normas profissionais e sociais; tempo etc. (CHOO, 1999, 2003; 2006).

Em resumo, a literatura sobre os estudos de NI parece ter evoluído no sentido de colocar o usuário da informação como centro de interesse em vez dos sistemas de informação que ele usa. Nesse paradigma, existem algumas correntes que se diferenciam pela maneira de perceber o usuário e suas necessidades. Enquanto um grupo de autores percebe o usuário por meio dos problemas que ele tenta resolver, outro grupo procura captar o que esse usuário considera como anomalia no seu estado de conhecimento diante de uma situação problemática. Um terceiro grupo de autores tenta entender como o usuário atribui sentido para o seu mundo por meio da maneira como ele usa a informação. Assim, os estudos sobre as NIs parecem estar seguindo linhas teóricas que se complementam, mas que normalmente não são reunidas quando se realiza uma pesquisa. A maioria das pesquisas procura seguir uma ou outra vertente teórica, seja por causa do formato conceitual, seja para adotar determinada metodologia.

O estudo da literatura da área aponta para a falta de uniformidade conceitual e ausência de metodologias abrangentes. No que concerne ao presente trabalho, pretendeu-se buscar a uniformidade conceitual. Pareceu frutífero, sob esse ponto de vista, reunir as vertentes teóricas em seus pontos semelhantes, considerando-as não como divergentes, e sim complementares. As NIs podem ser vistas, conjuntamente, a partir do entendimento do problema ou da situação problemática de um usuário de informação e também pela forma com que o usuário constrói sentido para seu

FIGURA 1 mundo e a partir disso busca, escolhe e usa a informação disponível. A construção de sentido, a busca da informação para a construção do conhecimento, e o uso da informação e do conhecimento para resolver problemas parecem ser os três fatores que ligam todas as vertentes de estudo das NIs.

\section{Elementos conceituais e dimensões das NIs}

Choo reuniu os aspectos propostos pelas abordagens alternativas para os estudos de usuários, considerando o usuário em seus aspectos cognitivo, situacional e emocional. Wilson, na mesma linha, analisou ainda o ambiente que influencia o "papel trabalho" do indivíduo (as variáveis intervenientes e os mecanismos de ativação). O construto formulado para o presente trabalho propõe a junção dessas duas abordagens formando um único "modelo" para estudar as NIs.

A figura 1 mostra os elementos e dimensões que definem as NIs individuais: as condições cognitivas, afetivas, e situacionais; e as necessidades ambientais, socioeconômicas e políticas. Busca-se entender como os fatores pessoais e ambientais influem na forma pela qual as pessoas constroem sentido para o mundo que as cerca e resolvem problemas na busca de atingir objetivos traçados para uma atividade. De acordo com a figura 1 , as

Dimensões e elementos das necessidades de informação individuais

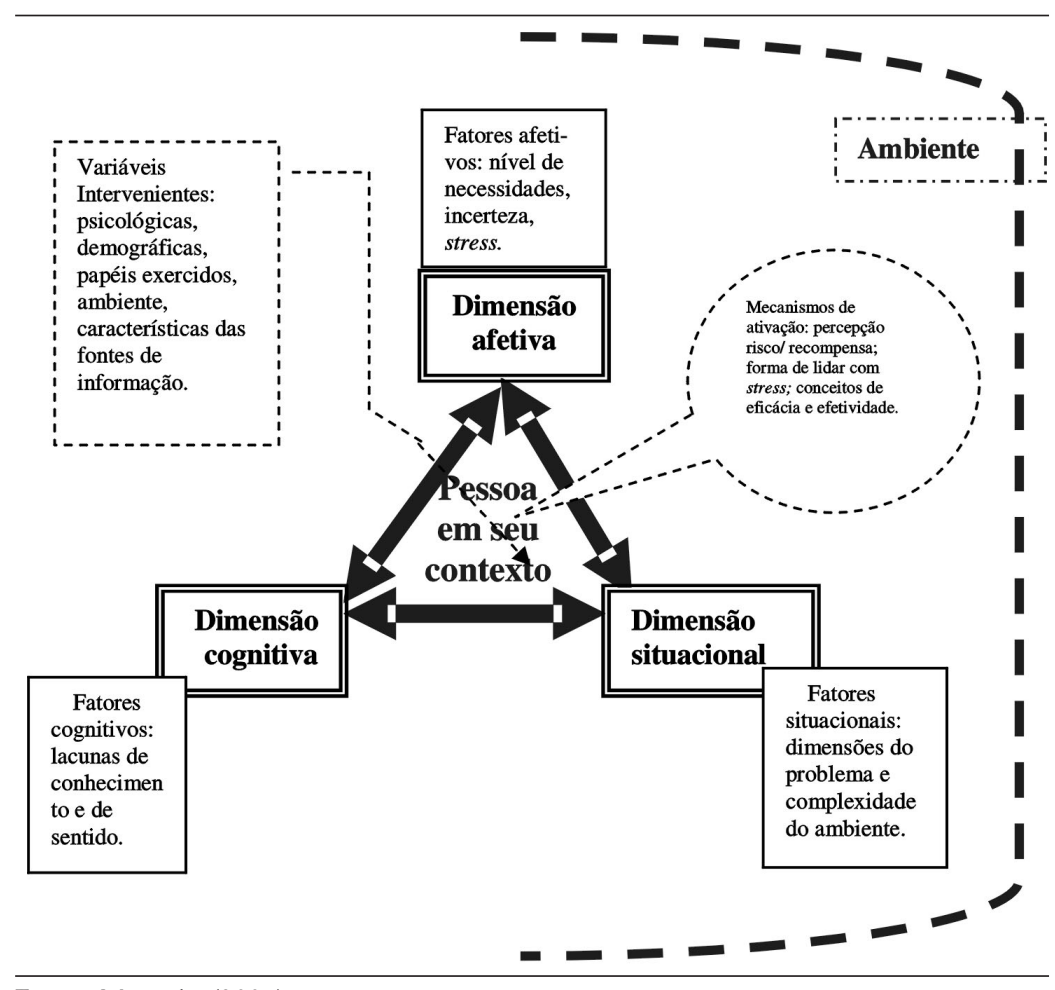

Fonte: Miranda (2007). 
necessidades individuais de informação em dado contexto podem ser definidas por fatores advindos das dimensões cognitivas, situacionais e afetivas referentes ao indivíduo, sua atividade e sua história de vida.

Ao realizar um trabalho, uma pessoa pode perceber que existem lacunas no seu entendimento sobre assuntos relativos às tarefas afeitas a esse trabalho. Essas lacunas podem ser relativas ao conhecimento necessário para realizá-lo e/ou ao significado da situação em que ele se desenvolve. Supõe-se que, ao solucionar determinado problema ou preencher uma lacuna cognitiva, o indivíduo escolhe suas fontes de informação de acordo com o seu conhecimento prévio sobre elas, com a experiência positiva ou negativa no seu uso, e pelo resultado obtido com seu uso anterior em situações semelhantes. Essa dimensão está ligada aos aspectos cognitivos das NIs individuais.

Segundo Belkin (1980; 1982), as NIs nascem do reconhecimento de uma anomalia (ou inadequação ou incoerência) no estado de conhecimento da pessoa com respeito a um tópico ou situação $\left(\mathrm{ASK}^{*}\right)$. Ele chegou a essa idéia adotando um ponto de vista cognitivo que admite que interações humanas são mediadas por estados de conhecimento sobre eles mesmos, aqueles com os quais interagem, e/ou sobre as situações problemáticas que enfrenta. A NI é, então, reconhecida como um estado, um processo que se modifica de acordo com a redução da incerteza no processo de aquisição de informações sobre o problema a ser solucionado. $O$ que se deve investigar para atender às NIs são a natureza das necessidades e a estrutura dos estados de conhecimento.

Dervin (1998) estudou as NIs com foco na construção de sentido e suas implicações para a gestão do conhecimento, conceituando o conhecimento a partir da ação/ atividade (from noum to verb). É a ação de conhecer, de formular sentido para o mundo a partir do caos (diversidade, complexidade, incompletude**), que determina as NIs. Tal como Belkin, Dervin utiliza uma abordagem cognitiva para estudar as NIs, definindo que

\footnotetext{
* Belkin (1980, p. 136) propôs o que ele denominou hipótese ASK, a partir da junção dos conceitos de Taylor, Kochen, e Wersig, na qual se reconhece que uma NI não é específica ou, normalmente, não pode ser especificada. Resulta daí a percepção de um estado de inadequação ou anomalia no estado de conhecimento que pode impedir uma pessoa de solucionar problemas.

** De acordo com Dervin (1998, p. 39), o sense-making é uma metáfora, dado que o conhecimento de hoje representa um esforço para o amanhã; que diz respeito à tentativa de resolver descontinuidades por meio de ações paulatinas, seqüenciais e situacionais, construindo pontes entre um momento e o outro no tempo, espaço e movimento.
}

estas nascem de "problemas cognitivos" que aparecem ao estudar problemas e tentar solucioná-los. As duas interpretações não são contraditórias, antes complementares, podendo-se definir as NIs como provenientes tanto da necessidade de suprir anomalias no estado de conhecimento, quanto da construção de sentido para poder solucionar problemas e situaçõesproblema.

Outros fatores que podem influir nas NIs são os papéis exercidos pelo indivíduo no ambiente (como o "papel trabalho") e a complexidade dos problemas e do ambiente. Esses fatores compõem aspectos situacionais que determinam certos comportamentos e ações das pessoas em um ambiente qualquer, compondo uma dimensão que pode ser denominada situacional no que concerne às NIs dos indivíduos em um contexto. Para Taylor (1986), o ambiente de uso da informação (geográfico, organizacional, social/intelectual/cultural) é definido como um conjunto de elementos que afeta o fluxo e o uso das mensagens, define entidades ou grupos de clientes e determina o critério pelo qual o valor da informação será julgado em um dado contexto. A análise desse ambiente de uso precisa ser traduzida em termos de informação, especialmente em organizações, onde se precisa monitorar, adaptar e interpretar informações externas ao contexto informacional interno e às necessidades internas de decisão. $\bigcirc$ valor agregado da informação está justamente nesse processo de "tradução", que é situacional, pois depende de cada organização, de cada ambiente, de cada grupo de pessoas e problemas, tornando o processo de julgamento do custo e benefício das informações e sua análise mais dramático e complexo.

As NIs são determinadas por problemas que emergem de situações específicas. Assim, os "ambientes-problema" que definem contextos onde as NIs nascem devem ser entendidos para que decisões sejam tomadas e objetivos atingidos, fazendo parte de um processo que vai de um estado inicial de delineamento do problema até o estágio final das ações/atividades. As características das informações (quantidade, opções, precisão, especificidade etc.) são importantes para a necessidade de informação. As dimensões dos problemas (estruturados ou não, complexos/simples, hipóteses e conjecturas, padrões, conseqüências, imposições) estabelecem critérios para julgamento de relevância das informações para os problemas (MACMULLIN; TAYLOR, 1984).

Ao perceber lacunas cognitivas ou de sentido em uma situação problemática, uma pessoa busca por informação 
guiada pelos níveis de necessidade e incerteza, que também dependem das dimensões do problema a ser solucionado e da complexidade do ambiente. Entretanto, os fatores advindos do ambiente podem ser intervenientes ou ativadores, afetando a percepção do indivíduo e sua forma de agir para buscar a informação que necessita. Essa é uma dimensão que pode ser denominada afetiva ou emocional, na medida em que é composta de fatores afetivos: são os sentimentos de segurança ou insegurança diante da incerteza e complexidade da situação que guiam o indivíduo na busca e uso da informação para solucionar problemas ou atingir objetivos.

A partir da abordagem cognitiva, Kuhlthau (1991; 1993) propôs o "princípio da incerteza" para considerar a gama de indeterminação nas associações mentais que caracteriza o pensamento humano. Em uma visão construtivista, admite que a busca de informação para formulação de um ponto de vista (sentido) em um assunto qualquer, dentro de uma estrutura de referência, é feita por meio de uma série de escolhas que transformam informações em significados. Esse processo envolve incerteza, dúvida e apreensão. $\bigcirc$ processo como um todo não envolve somente pensamento e ação, mas também sentimentos, que vão da confusão e da frustração à clareza e ao otimismo, dependendo dos resultados da assimilação de cada nova informação ao quadro de referência usado pela pessoa para estender seu conhecimento sobre um assunto. Wilson $(1996 ; 1999)$ ressalta que o processo informacional é sistêmico. Sendo assim, vários fatores interferem nesse processo, induzindo sentimentos de incerteza que podem interferir na decisão de buscar ou não informações. Estes fatores são stress e maneiras de lidar com o stress; percepção de risco recompensa diante da incerteza; preocupação em cometer erros ou não responder a expectativas, em infringir leis ou regulamentos, ou com responsabilidades financeiras; necessidade de resolver problemas e a crença em possuir informações com a quantidade e/ou qualidade necessárias.

Com base nos autores abordados e no construto representado pela figura 1 , define-se necessidades de informação como um estado ou um processo no qual alguém percebe a insuficiência ou inadequação dos conhecimentos necessários para atingir objetivos e/ou solucionar problemas, sendo essa percepção composta de dimensões cognitivas, afetivas e situacionais.

\section{AS COMPETÊNCIAS}

\section{A literatura sobre competências}

A abordagem da competência, no nível individual, pode ser considerada como proveniente da busca de alternativas de direcionamento para programas de educação e gestão das relações de trabalho dadas as novas condições socioeconômicas surgidas com a passagem para a sociedade pós-industrial. Podem ser caracterizadas duas correntes tratando do assunto: 1) uma referente à gestão de recursos humanos, que preconiza o uso da competência para integrar as atividades de gestão de recursos humanos por meio do seu uso em processos de seleção, treinamento, avaliação e remuneração; 2) outra referente à sociologia da educação e do trabalho, que trata dos aspectos psicossociais da utilização da competência nos programas educacionais nos níveis de qualificação da mão-de-obra e de emprego (GUIMARÃES, 2000).

Para Zarifian (2001), a abordagem da gestão de recursos humanos faria parte de uma primeira geração de ferramentas de gestão de recursos humanos, que, sob o rótulo de gestão de competências, interessou-se pelo ser humano como "recurso" a ser permanentemente desenvolvido e atualizado. Trata-se o ser humano de maneira economicista, o que pode fazer morrer a lógica da competência devido à sua compressão entre uma aparelhagem burocrática e uma interpretação estritamente individualizante. Para corrente teórica da sociologia da educação e do trabalho, ao contrário da corrente de recursos humanos, usar a "lógica da competência" significa uma mudança radical com respeito ao modelo do posto de trabalho, que é característico da sociedade industrial. A competência está centrada na mudança de comportamento social dos seres humanos em relação ao trabalho e à sua organização. Não se trata mais da qualificação para o emprego, e sim da competência de um indivíduo manifestada e avaliada na sua utilização em situações profissionais.

A estrutura organizacional e a organização do trabalho guardam correlação, enquanto partes de uma determinada relação social de produção. A sociedade feudal, as corporações e o modelo das profissões formaram um conjunto histórico e econômico-social. A sociedade industrial, as fábricas e modelo do posto de trabalho formaram um outro conjunto. As partes componentes do conjunto socioeconômico pertencente à sociedade pós-industrial ainda estão sendo definidas. A lógica da competência pertence a esse último conjunto histórico, estando ligada a três conceitos essenciais, segundo 
Zarifian (2001): o evento (o trabalho não está mais ligado a regularidades, e sim a acontecimentos inesperados); a comunicação (passa a ser um componente essencial do trabalho para a resolução de problemas); e o serviço (trabalhar torna-se gerar um serviço). Foram as mutações intensas do trabalho que introduziram esses conceitos, e eles ajudam a esboçar o conteúdo do que se pode entender como competência.

conceito de competência foi por vezes influenciado pela sua utilização no campo da gestão organizacional, gerando variadas conotações que podem ser reunidas em duas grandes correntes: a da literatura americana e a da literatura francesa. Os autores norte-americanos tratam a competência como um estoque de qualificações que credencia o exercício de determinado trabalho (normalmente associadas a demandas de determinados cargos); e os autores franceses associam a competência às realizações da pessoa em determinado contexto (agregação de valor - produção no trabalho independente do cargo) (CARBONE et al., 2005; DUTRA, 2004).

Na abordagem americana, McClelland (1973) começou a estruturar o conceito de competência na década de 1970 questionando os testes de aptidão intelectual, comuns nos EUA, como forma de avaliar performance profissional. $\mathrm{O}$ autor observou que as medidas de proficiência no trabalho dependiam de vários outros fatores (como hábitos, valores, interesses etc.), além da inteligência (avaliada pelos testes psicológicos). A competência seria uma abordagem alternativa de avaliação da performance, em vez dos testes de inteligência." Boyatzis (2004) questionou outra idéia, também corrente, de que uma gerência (ou liderança) efetiva estava diretamente relacionada à quantidade adquirida de conhecimento. Para o autor, a eficiência estaria no uso do conhecimento "para fazer as coisas acontecerem" (que ele chamou de competência). As competências seriam características que proporcionam resultados efetivos - incluindo habilidades cognitivas ou intelectuais -, habilidades intrapessoais e habilidades interpessoais. Além do conhecimento e das competências, uma performance acima da média requer o desejo de desenvolver e usar os talentos; e esse desejo é dirigido pelos valores, crenças, motivos e características pessoais* ${ }^{* *}$ Nessa abordagem,

\footnotetext{
* Pode-se imaginar quão revolucionária deve ter sido essa idéia, na medida em que ela questionava não só as afirmações de psicólogos da época sobre a validade dos testes de inteligência, mas também, de certa forma, começava a questionar a validade do formato educacional vigente para formar profissionais para o trabalho.

${ }^{* *}$ Para Boyatzis (2004), as habilidades intra e interpessoais comporiam o que ele denominou de "inteligência emocional", conceito com o qual ele passou a trabalhar mais tarde.
}

segundo Dutra (2004), não se abandona o referencial do posto de trabalho. A idéia da performance superior é analisada com relação ao estoque de qualificações que determinadas pessoas apresentam, que pode desdobrarse, por vezes, em uma parte chamada soft (traços de personalidade) e outra chamada hard (habilidades exigidas para um trabalho específico).

$\mathrm{Na}$ abordagem francesa, ter competência é saber mobilizar e combinar recursos (pessoais e do meio). É, também, a faculdade de usar essa dupla instrumentalização de recursos de maneira pertinente, ou a capacidade de integrar saberes diversos e heterogêneos para finalizá-los na realização de atividades. A lógica de integração do saber, do saber-fazer e dos comportamentos se estabelece em função das exigências da situação de trabalho. A competência profissional não reside nos recursos a mobilizar (conhecimentos, capacidades etc.), mas na própria mobilização desses recursos (itálico no original). A passagem do saber à ação é uma reconstrução: um processo de agregação de valor. A forma sistemática das "competências mobilizadas" corresponde ao trio "saberes, saber-fazer, saber-ser" (LE BOTERF, 2003).

A competência profissional é um processo de ativação de recursos, de reunião de condições favoráveis à realização e de superação dos possíveis obstáculos. É a tomada de iniciativa e o assumir responsabilidade, por parte do indivíduo, sobre problemas e eventos que ele enfrenta em situações profissionais, referindo-se a recursos que possuímos ou adquirimos e que sabemos como colocar em ação em uma situação prática. É uma inteligência prática das situações que, apoiando-se em conhecimentos adquiridos, transforma-os à medida que a diversidade das situações aumenta. É, também, a iniciativa sob a condição de autonomia, pressupondo a mobilização dos recursos internos pessoais (adquiridos, solicitados e desenvolvidos pelos indivíduos em dada situação) e dos coletivos (trazidos e colocados à disposição pelas organizações). É saber agir em um contexto de prescrições abertas, no qual as exigências profissionais deverão tomar a forma de critérios de orientação (que serão interpretados e traduzidos) e não de procedimentos. Isso implica diferenciar a competência requerida (descrita em termos de objetivos/ missões, exigências profissionais, condições, objetivos a atingir em determinadas condições) e a competência real (esquema operatório ou estrutura geral subjacente à ação - disposição para agir, saber combinatório - não pode ser apreendido diretamente, mas pode ser observado em uma atividade). Competência real é uma "equação pessoal" (LE BOTERF, 2006; ZARIFIAN, 2001; 2006). 


\section{A literatura brasileira sobre competências}

Fleury e Fleury (2001) definem competência como um saber agir responsável e reconhecido, que implica mobilizar, integrar, transferir conhecimento, recursos, habilidades, que agreguem valor econômico à organização e valor social ao indivíduo. Dutra (2001) adota o conceito de competência reconhecido por outros teóricos: conjunto de conhecimentos, habilidades, e atitudes; mas acrescenta a dimensão entrega (em atos e realizações). Segundo ele, o conceito de entrega é equivalente ao que Fleury e Fleury chamam "saber agir responsável e reconhecido". Pode-se dizer, também, que o conceito de entrega em Dutra assemelha-se ao de mobilização em Zarifian. Carbone et al. (2005) adotaram uma definição similar às dos autores anteriores:

combinações sinérgicas de conhecimentos, habilidades e atitudes expressas pelo desempenho profissional dentro de determinado contexto organizacional que agregam valor a pessoas e organizações.

O Conselho Nacional da Educação, órgão do governo brasileiro, definiu competência profissional (individual) como

a capacidade pessoal de mobilizar, articular e colocar em ação conhecimentos, habilidades, atitudes e valores necessários para o desempenho eficiente e eficaz de atividades requeridas pela natureza do trabalho e pelo desenvolvimento tecnológico*.

Esse conceito se diferencia de algumas definições pela inclusão do item valores como elemento separado das atitudes. Alguns autores se referem, também, a comportamentos, como desempenho expresso, em que a competência pode ser realmente observada (BRASIL, 2002; CARBONE et al., 2005)

Na avaliação de Carbone et al. (2005), a literatura norteamericana entende a competência como um estoque de qualificações e os autores franceses associam a competência às realizações da pessoa em determinado contexto. Para esses autores, a competência deve ser entendida não apenas como um conjunto de conhecimento, habilidades e atitudes, mas também em termos de comportamentos e realizações decorrentes da mobilização e aplicação desse conjunto de recursos no trabalho, em uma combinação sinérgica dentro de determinado contexto organizacional.
Um aspecto interessante da competência individual é que a visão da pessoa sobre si mesma pode influenciar sua percepção/avaliação com relação à própria competência. Pesquisas mostraram que a percepção das pessoas sobre sua própria competência é independente dos resultados reais obtidos em testes de conhecimento, por exemplo. Quando uma pessoa não tem conhecimento suficiente para avaliar seus resultados, ela, normalmente, os avalia mal, porque the faltam habilidades metacognitivas necessárias para fazer uma avaliação correta, ou seja, as pessoas podem estar "inocentes" sobre sua própria competência (KRUGER; DUNNING, 1999; EHRLINGER; DUNNING, 2003; DUNNING et al., 2003). Portanto, entre as habilidades a serem demonstradas em uma prática competente, deveriam estar as habilidades metacognitivas, que envolvem a habilidade para distinguir o que é correto e o que é incorreto e para avaliar a performance das outras pessoas. Ou seja, conhecer suficientemente um assunto, por exemplo, possibilita distinguir o certo do errado nesse assunto; sem essa percepção, não se poderia avaliar corretamente a competência das outras pessoas, o que se traduziria em falsa avaliação da própria competência. Isso significa que a identificação de uma competência não pode estar baseada somente na autopercepção do indivíduo em seu próprio trabalho.

Resumindo, a literatura sobre competências, no nível individual, apresenta uma divergência teórica que parece inconciliável. Enquanto uma vertente não diferencia a "lógica da competência" da "lógica do posto de trabalho", a outra opõe essas duas lógicas. Os argumentos teóricos que não confundem a lógica da competência com a do emprego parecem mais coerentes para explicar a nova forma de qualificação para o trabalho surgida na sociedade pós-industrial. Inclusive, no que concerne ao mapeamento e análise de competências, evitariam que se ficasse preso a uma estrutura de cargos e salários que poderia destruir o próprio conceito de competência e a sua utilidade. A competência deve ser avaliada nas situações práticas de trabalho e não pode estar amarrada a uma estrutura previamente estabelecida. No entanto, não se pode dizer que já existe uma definição clara sobre as opções teóricas para todos os autores. Essa área de estudo ainda está se desenvolvendo em teoria e prática.

Com base nos conceitos expostos, define-se competência como o conjunto de recursos e capacidades colocado em ação nas situações práticas do trabalho: saber (conhecimentos), saber-fazer (habilidades) e saber-ser/ agir (atitudes).

"Art. 7º da Resolução CNE/CP no 3. 
As competências informacionais

A competência informacional pode ser definida, com base no conceito anterior, como um conjunto de competências individuais que possa ser colocado em ação nas situações práticas do trabalho com a informação. Ela pode ser expressa pela expertise em lidar com o ciclo informacional, com as tecnologias da informação e com os contextos informacionais*. Essa competência poderá, provavelmente, ser relacionada às competências de um profissional de informação (MIRANDA, 2004 e 2007).

Um problema central para o modelo da competência, segundo Zarifian (2003), é como organizar e estruturar as informações para facilitar a comunicação. A informação é o que especifica, seleciona ou singulariza as solicitações, em vista de uma conduta profissional bem-sucedida. $\bigcirc$ que importa em uma situação profissional é a informação pertinente sobre o que alguém solicita tendo em vista a ação, permitindo ao indivíduo situar-se no meio ambiente e agir.

A competência informacional mobilizada em situações de trabalho pode ser vista como um dos requisitos do perfil profissional necessário para trabalhar com a informação, não importando o tipo de profissional ou de atividade. É uma competência que perpassa processos de negócio, processos gerenciais e processos técnicos diversos, bem como diferentes partes de uma mesma organização ou atividade. Ela pode ser comparada ao que Zarifian (2001) denomina competências de fundo: elas são adquiridas em situação educativa e formalizadas em conquistas cognitivas e comportamentais necessárias para enfrentar as categorias de situações-problema em que o trabalho com a informação tem papel primordial, mesmo que não apareça no resultado final da atividade.

\footnotetext{
* O ciclo informacional identifica todas as fases do trabalho com a informação. A tecnologia da informação (TI) pode ser definida como tecnologia que influi na arquitetura do conhecimento (suporte, formato, conteúdo e tipo) e que, na "era da informação", envolve computadores, telecomunicação e sistemas de software que ajudam a organização, transmissão, armazenamento e utilização de dados, informações e/ou conhecimentos. O contexto informacional é o contexto onde se realiza o ciclo informacional e que influencia no seu fluxo e em suas características diferenciando tipos de informação: informação tecnológica, informação para negócios, informação científica e outros.
}

Essa competência pode ser desenvolvida para possibilitar que um usuário de informação atenda a suas próprias necessidades de informação.

\section{As dimensões das competências informacionais}

Considera-se que existe uma "relativa unanimidade" entre os autores da área na consideração da competência como um conjunto de recursos que compreende: conhecimentos, habilidades e atitudes. Um construto relativo à competência informacional, reunindo conceitos provindos da literatura consultada, pode ser representado conforme a figura 2 .

A competência informacional pode ser definida em torno de três dimensões relacionadas ao saber (conhecimentos), saber-fazer (habilidades) e saber-agir (atitudes). O conhecimento refere-se a "crenças verdadeiras e justificadas", conceito buscado em Platão por Nonaka e Takeushi (1995). Segundo os autores, a discussão sobre esse conceito divide-se entre algumas correntes, mas ainda persiste no pensamento ocidental o dualismo cartesiano que considera a separação entre mente e corpo, sujeito e objeto. A cultura oriental, ao contrário, considera a existência do "conhecimento subjetivo" e da inteligência intuitiva. Para Hessem (2003), o verdadeiro problema do conhecimento coincide com a questão sobre a relação entre sujeito e objeto. Com respeito à relação sujeito-objeto, Varela (1991) declara: aquele que sabe (sujeito) e aquilo que é sabido (objeto) especificam-se recíproca e simultaneamente um ao outro. 
Para fins do presente estudo, considera-se o conhecimento sob um ponto de vista integrativo com respeito às fontes: tanto o pensamento (razão) como a experiência são fontes de conhecimento. $\mathrm{O}$ sujeito, no seu contexto, vale-se tanto da razão quanto da experiência para construir seu conhecimento. Conforme ressalta Valentim (2005), o conhecimento possui propriedades inerentes ao sujeito que o constrói, podendo-se entendê-lo como sendo único e dependente de estruturas teóricas e práticas que possibilitam sua construção. Os saberes são os conhecimentos profissionais de base explicitamente transmissíveis (formais, declarativos), podendo ser traduzidos em fatos e regras (STROOBANTS, 2004).

As habilidades podem ser relacionadas à capacidade de aplicar e fazer uso produtivo do conhecimento adquirido, ou à capacidade de buscar em experiências anteriores informações apropriadas para examinar e solucionar um problema. Um profissional deve saber administrar dois tipos de critérios: o das "prescrições", que diz respeito ao referencial profissional da ocupação (o que se pode fazer), e o de "especificações", que são as características das atividades e dos produtos que são desejadas pelos clientes (o que se quer que seja feito). É o contexto profissional e as situações profissionais que determinam o saberfazer. O saber-fazer é o conjunto de noções adquiridas na prática, procedimentos empíricos (receitas e truques do ofício) que não podem ser padronizados (heurísticos) (LE BOTERF, 2003; STROOBANTS, 2004).

As atitudes referem-se a aspectos sociais e afetivos, a preferências e interesses, a condicionantes do esforço e do controle exigidos para expressar ou adotar um comportamento desejado. É o sujeito, sua biografia e socialização que determinam o saber-agir. A cultura* fornece ao profissional a "caixa de ferramentas simbólicas" com a qual ele modelará seus esquemas de comportamentos adaptativos. O saber-ser é o conjunto das qualidades pessoais, saberes sociais, de senso comum, que aparecem nos casos em que o problema a resolver não pode ser "dado" ou representado (BRANDÃO, 1999; LE BOTERF, 2003; STROOBANTS, 2004).

As dimensões da competência informacional podem ser exemplificadas como: 1) conhecimentos sobre a arquitetura e o ciclo da informação; como obter produtos e serviços de informação; como selecionar fontes, canais, contextos e tecnologias adequados de informação para

\footnotetext{
* Para LeBoterf (2003), essa cultura refere-se a sistemas de valores e significações, modelos que são socialmente partilhados. Ela tanto pode dizer respeito ao meio social, quanto à organização na qual se trabalha, quanto à profissão.
}

solucionar problemas específicos de usuários de informação específicos; 2) habilidades de detectar necessidades; avaliar o custo/benefício da busca e uso da informação para solucionar problemas; lidar com a TI; 3) atitudes de integridade, controle e compartilhamento, transparência, proatividade - uma "cultura informacional" rica e positiva capaz de avaliar o valor da informação para cada usuário no intuito de atender suas necessidades. O que especifica conhecimentos, habilidades e atitudes de um usuário que desenvolve a competência informacional é a sua eficiência e efetividade em reconhecer suas necessidades de informação e atendê-las para cumprir objetivos em suas tarefas e resolver seus problemas informacionais.

\section{O RELACIONAMENTO ENTRE AS NIs E AS COMPETÊNCIAS}

As três dimensões das NIs foram reunidas por Choo e Wilson, principalmente a partir dos trabalhos de Dervin (cognitiva), Kuhlthal (emocionais) e Taylor (situacionais). Nesse construto, as NIs são caracterizadas por uma percepção do vazio cognitivo e pelas estratégias para preenchê-lo. Elas podem ser representadas pelos estados emocionais de ansiedade, confusão, frustração e dúvida, que acompanham a incerteza envolvida na busca do preenchimento do vazio cognitivo, e pelos requisitos, normas e expectativas provenientes do ambiente de trabalho do usuário da informação que determinam as percepções compartilhadas nesse ambiente sobre o que constitui a solução de um problema. Entre os elementos que determinam o uso da informação, estão 1) a sua relevância e pertinência para o esclarecimento da questão ou solução do problema, que são elementos subjetivos, cognitivos, situacionais, multidimensionais e dinâmicos; 2) as atitudes do usuário em relação à informação e à sua busca, que são fruto da sua educação, treinamento, experiência passada, preferências pessoais etc.

Considerou-se, assim, que as NIs são determinadas por fatores de natureza cognitiva, psicológica e social (cognitivo-afetivo-situacional) que revelam a existência de problemas a resolver, anomalias ou insuficiências nos conhecimentos acumulados, ou perda de sentido com relação ao ambiente vivido e à forma de lidar com ele. Para analisar e diagnosticar as NIs, precisar melhor as anomalias e insuficiências de conhecimento e formular com mais clareza as questões necessárias que solucionem os problemas existentes, é necessário adquirir competências particulares. Por exemplo, competências interacionais (comunicacionais) e competências de diagnóstico, que permitam a um profissional tornar-se um engenheiro do conhecimento, um conselheiro em 
informação e conhecimento etc. (LE COADIC, 1998; CHOO, 2006).

A competência, que também pode ser considerada como uma "construção social"*, representa a forma pela qual uma pessoa pode dotar-se de possibilidades para construir sua ação no mundo que a cerca, relacionando o conhecimento e sua aplicação. O entendimento da competência em suas naturezas cognitiva, social e psicológica (conhecimentos-habilidade-atitudes) revela a complexidade do processo de aprendizagem que relaciona o pensamento à ação. O que determina a competência do indivíduo é o conhecimento social e a inteligência prática**. A competência encontra seus limites no nível dos saberes alcançado pela sociedade ou pela profissão do indivíduo em uma época determinada. Ou seja, a NI para ação em um contexto dado se esbarra no desenvolvimento das competências para lidar com essa informação e/ou com esse contexto. São como "duas faces da mesma moeda", por assim dizer (STROOBANTS, 2004; TANGUY, 2004; BRANDÃO, 1999; FLEURY; FLEURY, 2001a).

No plano das definições teóricas, as necessidades de informação e as competências partilham, então, dimensões constitutivas semelhantes, conforme mostra a figura 3. Tanto as NIs quanto as competências podem ser entendidas nas três dimensões consideradas: cognitiva, emocional e situacional. $\mathrm{O}$ saber pode ser construído por relações cognitivas internas ao indivíduo, influenciado por suas interações com o ambiente. As diferentes situações com as quais se depara o indivíduo para solucionar problemas podem proporcionar habilidades diferenciadas para lidar com dado contexto ao longo do tempo. As emoções advindas de experiências e percepções vividas durante o processo de geração de conhecimento e de aquisição de habilidades podem guiar

\footnotetext{
* Stroobants (2004) ressalta que as competências são relativas porque dependem da maneira pela qual são vistas. Deve-se, também, levar em conta os processos locais no decorrer dos quais os atores valorizam suas competências. Assim, é necessário considerar a competência como um "construto" que depende do meio no qual é revelado.

** O conhecimento social é aquele construído durante uma longa trajetória histórica da sociedade na qual se insere o indivíduo, servindo para orientá-lo. Esse conhecimento se particulariza à medida que o indivíduo se apropria dele e o questiona em sua trajetória de socialização. $\mathrm{O}$ núcleo da inteligência prática é a compreensão das situações, compreensão na qual, os conhecimentos do indivíduo são mobilizados (ZARIFIAN, 2003; 2004).
}

a atitude dos indivíduos diante de contextos diferenciados.

O conhecimento pessoal e profissional é estabelecido por relacionamentos entre uma estrutura cognitiva e conceitual preexistente e as experiências proporcionadas para adquiri-lo em um contexto dado. O que se sabe fazer está ligado às habilidades que puderam ser desenvolvidas nas situações já vivenciadas e problemas já solucionados. O saber-agir está ligado aos laços estabelecidos entre os saberes adquiridos e as soluções formuladas para determinadas situações por meio de uma "memória emocional" que ficou conectada à escolha dos caminhos tomados. Dessa forma, pode-se considerar que soluções encontradas para atender a uma NI provavelmente corresponderam a competências desenvolvidas para lidar com os problemas informacionais solucionados, com as anomalias/insuficiências de conhecimento diante de situações vivenciadas, ou com os vazios de sentido diante de modificações do ambiente informacional.

\section{CONSIDERAÇÕES FINAIS}

\section{Segundo Choo (2003),}

“... a informação e o insight nascem no coração e na mente dos indivíduos, e (...) a busca e o uso da informação são um processo dinâmico e socialmente desordenado que se desdobra em camadas de contingências cognitivas, emocionais e situacionais.

$\mathrm{O}$ autor considera que a busca e o processamento da informação são fundamentais em muitos sistemas sociais e atividades humanas, e a análise das necessidades e dos usos da informação vem se tornando um componente cada vez mais importante da pesquisa em áreas como a psicologia cognitiva, estudo da comunicação, difusão de inovação, recuperação da informação, sistemas de 
informação, tomada de decisões e aprendizagem organizacional.

Os estudos orientados para o usuário nas abordagens mais recentes vêem a informação como uma construção subjetiva, em que o valor da informação reside no relacionamento que o usuário constrói entre si mesmo e determinada informação. Portanto, devem ser examinadas as preferências e necessidades cognitivas e psicológicas do indivíduo e também como elas afetam a busca e os padrões de comunicação da informação. Isso envolve a busca dos motivos que geram as NIs e de como essas necessidades são percebidas representadas, definidas e vivenciadas. Também envolve entender como a informação ajuda o usuário a avaliar os resultados do uso: impacto; benefícios; contribuição para o desempenho (CHOO, 2003; 2006).

Nos estudos sobre NI, buscou-se a convergência teóricoconceitual, que tem sido preocupação dos estudos de usuários desde a década de 1980. Nessa época, delinearam-se as vertentes que pertencem ao que se denominou novo paradigma nos estudos de usuários, que pretendeu adotar o próprio usuário como centro de preocupação das pesquisas. Os autores escolhidos para compor o construto formulado expressam essa convergência. A dimensão cognitiva (componente cognitivo) se refere ao histórico, estrutura e estilos cognitivos dos usuários da informação. A dimensão situacional (componente sociológico, contextual) se refere às crenças e pressuposições que fazem parte da cultura do indivíduo e do ambiente onde ele vive e trabalha, as características do próprio ambiente, suas oportunidades e dificuldades, a estrutura dos problemas existentes e a crença sobre o que constitui a solução de um problema. A dimensão afetiva (emocionalcomponente psicológica) diz respeito ao histórico individual em termos da progressão dos pensamentos, sentimentos e percepções experimentados em momentos de confusão, incerteza, ansiedade, expectativa, acessibilidade e objetividade, que dirigiram as estratégias e as decisões na busca e uso da informação.

Uma lacuna "prática" na literatura sobre NI é a busca da construção de um cenário que habilite um usuário de informação a atender a suas necessidades com seus próprios recursos. $\mathrm{O}$ desenvolvimento da competência informacional é uma opção que poderia preencher essa lacuna. Ou seja, o desenvolvimento de competências específicas com relação ao trabalho informacional poderia ser proposto como forma de se preencher a lacuna existente entre o reconhecimento de uma NI e o seu atendimento. Entre o reconhecimento de uma necessidade e a ação no sentido de atendê-la, coloca-se a formação de competências que habilitem o pensamento a tornar-se ação, a transformação da informação em conhecimento e, também, a formação de habilidades e atitudes apropriadas para o trabalho com a informação.

A competência supõe que o trabalhador da era da informação volte a ser um "artesão" de sua própria qualificação, o que envolve o reconhecimento do papel essencial do contexto, a não-racionalização ou formalização de certas competências, e a descoberta de que os conhecimentos não são bastantes para um desempenho efetivo. A alta especialização não é suficiente, por não abarcar a complexidade do ambiente das tarefas, o que coloca atenção na identidade do trabalhador como sujeito cognitivo que constrói seu mundo e também sublinha a relação entre o conhecimento e a ação (STROOBANTS, 2004; TANGUY, 2004). Não basta reconhecer uma necessidade de informação para se obter o conhecimento necessário para solucionar problemas. É preciso reconhecer a complexidade do mundo da informação e da interação entre a informação e o sistema de conhecimentos (estrutura cognitiva) do usuário.

Em termos teóricos, a proposta do presente estudo foi que as necessidades de informação a serem identificadas poderiam corresponder à competências informacionais a serem desenvolvidas para atendê-las. $\bigcirc$ "modelo teórico" buscado procura mostrar tanto a convergência teórica quanto a compatibilidade das NIs com o desenvolvimento das competências. $O$ estado de percepção de um conhecimento anômalo ou insuficiente pode levar ao desenvolvimento de competência(s) específica(s) na busca da informação que vai supri-lo. Este desenvolvimento pode ser identificado, por exemplo, no trabalho do usuário ao lidar com o ciclo da informação, com os contextos e com a tecnologia da informação.

Uma das repercussões práticas aventadas a partir da conexão teórica formulada no presente estudo é que o processo de desenvolvimento da competência informacional ligada a NIs identificadas em determinado contexto pode fazer parte do trabalho educativo atinente aos denominados "profissionais de informação". Dado que esses profissionais lidam com a informação como instrumento de trabalho, fazendo a mediação entre a informação e os seus usuários, eles são profissionais que podem desenvolver a competência específica para o trabalho com a informação* educando os usuários da

\footnotetext{
* Para informações sobre os profissionais de informação, sua área de atuação e suas competências, consultar Valentin (2002 e 2004).
} 
informação no desenvolvimento de suas próprias competências.

Em termos práticos, as competências específicas desenvolvidas no trabalho com a informação podem habilitar um usuário a atender a suas próprias necessidades de informação (um empowerment* informacional). Na sociedade da informação, um usuário deve estar completamente integrado no mundo da informação e do conhecimento, de maneira a obter o melhor proveito de seus recursos de trabalho. Isso significa desenvolver competências específicas que envolvam esses recursos. Essas competências podem ser desenvolvidas a partir do reconhecimento das necessidades existentes em lidar com o mundo da informação, formando um ciclo criativo e evolutivo de reconhecimento de necessidades e desenvolvimento de habilidades e atitudes apropriadas que vai oferecer possibilidades de solucionar problemas.

De acordo com os construtos apresentados, as fontes de informação, os tipos e formatos de informação e de tecnologias de informação, os tipos e formatos de documentos e a forma de comunicação que atendem as NIs de usuários específicos são selecionados conforme suas características individuais e as condições de suas atividades. Isso faz com que essas necessidades sejam especificamente determinadas, e para atendê-las o usuário deva desenvolver competências específicas ligadas ao trabalho com a informação. A identificação das competências específicas capazes de atender a NIs específicas poderia ser efetuada a partir de parâmetros informacionais, como o uso da informação tendo como base as fases do ciclo da informação, a possibilidade de usar contextos informacionais diferentes para enriquecer o resultado obtido por alguma tarefa e o uso da tecnologia da informação para conseguir maior eficiência e efetividade na geração do conhecimento necessário para solucionar problemas.

Artigo submetido em 26/01/2006 e aceito em 23/04/2007.

\section{REFERÊNCIAS}

AUSTER, E.; CHOO, C. W. Managing information for the competitive edge. New York: Neal-Schuman Pub., 1996. 545 p.

BELKIN, Nicholas J. Anomalous states $\mathrm{f}$ knowledge as a basis for information retrieval. The Canadian Journal of Information Science, v. 5, p. 133-143, May 1980.

et al. Ask for information retrieval: part I: backfround and theory. Journal of Documentation, v. 38, n. 2, p. 61-71, June 1982.

BETTIOL, Eugenia M. Necessidades de informação na área de biotecnologia agro-pecuária no Brasil. 1988. Dissertação (Mestrado)- Universidade de Brasília, Brasília, 1988.

BOYATZIS, Richard E. Self-directed learning: develop your emotional intelligence. Executive Excellence, v. 21, n. 2, p. 11-12, Feb. 2004.

BRANDÃO, Hugo P. Gestão baseada nas competências: um estudo sobre competências profissionais na indústria bancária. 1999. Dissertação (Mestrado) - Universidade de Brasília, Brasília, 1999.

BRASIL. Ministério da Educação. Conselho Nacional da Educação. Resolução CNE/CP no 3, 23 de dezembro de 2002. Diário Oficial [da] República Federativa do Brasil, Brasília, 2002. Disponível em: < http:// www.mec.gov.br/ semtec/educprof $>$. Acesso em: 28 mar. 2004.

CALVA GONZÁLEZ, Juan J. La investigación sobre las necesidades de información en comunidades de usuarios. Investigación Bibliotecológica, v. 18, n. 87 , p. $23-35$, jul./dic. 2004.

CARBONE, Pedro P. et al. Gestão por competências e gestão do conhecimento. Rio de Janeiro: Editora FGV, 2005. 172 p.

CHOO, Chun Wei. A organização do conhecimento: como as organizações usam a informação para criar significados, construir conhecimento e tomar decisões. São Paulo: Editora Senac São Paulo, 2003. 425 p.

. Closing the cognitive gaps: how people process information. Financial Times, London, Mar 22, 1999.

Human information seeking behaviors. In: INTERNATIONAL CONGRESS ON ELECTRONIC MEDIA \& CITIZENSHIP IN INFORMATION SOCIETY, 2., 1999, Helsinki. Proceedings... Helsinki: Politics \& Internet Conference, 1999a.

DERVIN, Brenda. Sense-making theory and practice: an overview of user interests in knowledge seeking and use. Journal of Knowledge Management, v. 2, n. 2, p. 36-46, Dec. 1998.

; NILAN, M. Information needs and uses. Annual Review of Information Science and Technology - ARIST, v. 21, p. 3-33, 1986.

DUTRA, Joel de Souza (Org.). Gestão por competências. São Paulo: Editora Gente, 2001. 130 p.

FERREIRA, S. M. Estudo de necessidades de informação: dos paradigmas tradicionais à abordagem sense-making. $A B E D B$, n. 2, 1997. Disponível em: <http://www.eca.usp.br/nucleos/sense/textos/ sumar.htm>. Acesso em: 19 jun. 2005.

FIGUEIREDO, Nice M. Aspectos especiais de estudos de usuários. Ciência da Informação, v. 12, n. 2, p. 43-57, jul./dez. 1983.

FLEURY, A.; FLEURY, M. T. L. Estratégias empresariais e formação de competências: um quebra-cabeça caleidoscópico da indústria brasileira. 2. ed. São Paulo: Atlas, 2001. 169 p.

\footnotetext{
* A idéia de empowerment significa proporcionar ou investir alguém de algum poder, uma capacidade para realizar algo, e corresponde ao que foi traduzido em português por "empoderamento".
} 
Desenvolver competências e gerir conhecimentos em diferentes arranjos empresariais: o caso da indústria brasileira de plástico. In: FLEURY, M. T. L.; OLIVEIRA JR., M. de O. (Org.). Gestão estratégica do conhecimento: integrando aprendizagem, conhecimento e competências. São Paulo: Atlas, 2001a. p. 189-211.

GUIMARÃES, Tomás de A. A nova administração pública a abordagem da competência. RAP - Revista de Administração Pública, v. 34, n. 3, p. 124-40, maio/jun. 2000.

HESSEN, Johannes. Teoria do conhecimento. 2. ed. São Paulo: Martins Fontes, 2003.177 p.

HEWINS, ELIZABETH T. Information need and use studies. Annual Review of Information Science and Technology - ARIST, v. 25, p. 145-172, 1990.

KUHLTHAU, Carol C. A principle of uncertainty for information seeking. Journal of Documentation, v. 49, n. 4, p. 339-355, 1993.

. Inside the search process. Journal of the American Society for Information Science, v. 42, n. 5, p. 361-371, 1991.

LE BOTERF, Guy. Desenvolvendo a competência dos profissionais. 3. ed. rev. e amp. Porto Alegre: Artmed, 2003. 278 p.

. Construire le compétences individuelles et collectives. 4. ed. Paris: Éditions d'Organisations, 2006.

LE COADIC, Yves F. Le besoin d'information. Paris: ADBS Editions, 1998. $191 \mathrm{p}$.

MCCLELLAND, David. C. Testing for competence rather than for "intelligence". American Psychologist, v. 28, p. 1-14, Jan. 1973.

MACMUllin, S. E.; TAYLOR, R. S. Problem dimensions and information traits. The Information Society, v. 3, n. 1, p. 91-111, 1984.

MIRANDA, Silvânia V. Identificando competências informacionais. Ciência da Informação, v. 33, n. 2, p. 112-122, maio/ago. 2004.

. Identificação de necessidades de informação e sua relação com competências informacionais: o caso da supervisão indireta de instituições financeiras no Brasil. 2007. Tese (Doutorado em Ciência da Informação)- Universidade de Brasília, Brasília, 2007.

NIEDZWIEDZKA, Barbara. A proposed general model of information behaviour. Information Research, v. 9, n. 1, Oct. 2003. Disponível em: $<$ http://nformationR.net/ir/9-1/paper164.html >. Acesso em: $04 \mathrm{dez}$. 2004.

NONAKA, I.; TAKEUSHI, H. The knowledge-creating company: how japanese companies create the dynamics of innovation. New York: Oxford University Press, 1995. 284 p.

PETTIGREW, K. E.; FIDEL, R.; BRUCE, H. Conceptual framework in information behavior. Annual Review of Information Science and Technology, v. 35, p. 43-78, 2001.

PINHEIRO, Lena Vânia R. Usuário - Informação: o contexto da ciência e da tecnologia. Rio de Janeiro: LTC-Livros Técnicos e Científicos, $1982.66 \mathrm{p}$.

STROOBANTS, Marcelle. A visibilidade das competências. In: ROPÉ, F; TANGUY, L. (Org.). Saberes e competências: o uso de tais noções na escola e na empresa. 5. ed. Campinas: Papirus, 2004. 207 p.
TANGUY, Lucie. Racionalização pedagógica e legitimidade política. In: ROPÉ, F; TANGUY, L. (Org.). Saberes e competências: o uso de tais noções na escola e na empresa. 5. ed. Campinas: Papirus, 2004. $207 \mathrm{p}$.

TAYLOR, Robert S. Value-added processes in information systems. Norwood: Ablex Publishing Co., 1986. 257 p.

VALENTIM, Marta L. P. Construção de conhecimento científico. In: VALENTIM, M. L. P. (Org.). Métodos qualitativos de pesquisa em ciência da informação. São Paulo: Polis, 2005. p. 119-134.

Polis, 2004. $191 \mathrm{p}$. Atuação profissional na área de informação. São Paulo: 2002. $152 \mathrm{p}$. . Formação do profissional da informação. São Paulo: Polis,

VARELA, Francisco. Conhecer: as ciências cognitivas, tendências e perspectivas. Lisboa: Instituto Piaget, 1991. 100 p.

WALTER, Maria Tereza M. T. Necessidade de informação dos técnicos de nível superior da Engevix Engenharia S. A. 1988. Dissertação (Mestrado)Universidade de Brasília, Brasília, 1988.

WILSON, T. D. Philosophical foundations and research relevance: issues for information research. In: INTERNATIONAL CONFERENCE ON CONCEPTIONS OF LIBRARY AND INFORMATION SCIENCE, 4., 2002, Seattle. Emerging frameworks and method: electronic proceedings... Seattle (USA): University of Washington, 2002. Disponível em: < http://informationr.net/tdw/publ/ papers/COLIS4.html>. Acesso em: 27 set. 2005.

. Recent trends in user studies research and qualitative methods. Information Research, v. 5, n. 3, Mar. 2000. Disponível em: $<$ http://www.informationR.net/ir/5-3/paper 76.html>. Acesso em: 05 maio 2003 .

Models in information behaviour research. Journal of Documentation, v. 55, n. 3, p. 249-270, 1999. Disponível em: <http:// informationr.net/tdw/publ/papers/1999JDoc.html>. Acesso em: 25 jan. 2006.

. The cognitive approach to information-seeking behaviour and information use. In: SEMINAR ON THE PSYCHOLOGICAL ASPECTS OF INFORMATION SEARCHING, 1983, Copenhagen. Electronic proceedings... Disponível em: <http:// informationr.net/tdw/publ/papers/cogapp84.html >. Acesso em: $28 \mathrm{dez}$. 2003.

On user studies and information needs. Journal of Librarianship, v. 37, n. 1, p. 3-15, 1981. Disponível em: < http:// informationr.net/tdw/publ/papers/1981infoneeds.html $>$. Acesso em: 28 dez. 2003.

; WALSH, C. Information behaviour: an inter-disciplinary perspective. London: Report to British Library Research and Innovation Centre, 1996. Disponível em: <http://informationr.net/tdw/publ/ infbehav/>. Acesso em: 25 jan. 2006.

ZARIFIAN, Philippe. Le modèle de la compétence. 2. ed.. Paris : Éditions Liaisons, 2004.

. O modelo da competência: trajetória histórica, desafios atuais e propostas. São Paulo: Editora Senac São Paulo, 2003. 192 p.

Nota: este artigo teve como base a revisão bibliográfica e o referencial teórico formulados para pesquisa de doutorado orientada pela professora doutora Kira Tarapanoff. 